\title{
Outcome of Ilizarov External Fixator for Treatment of Comminuted Tibial Plateau Fractures
}

ISSN: 2576-8875

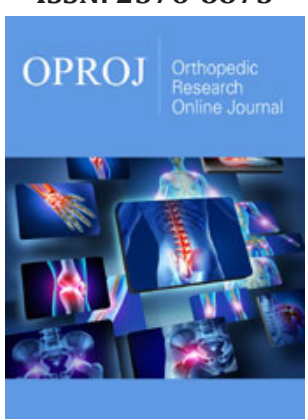

*Corresponding author: Ebeed yasin, Orthopaedic Department, Aswan University, Egypt

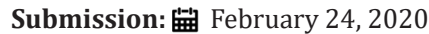

Published: February 27, 2020

Volume 6 - Issue 5

How to cite this article: Ebeed yasin MD, Faisal Adam MD, Hesham Refae MD, Abdallah Hussein Abdel-Fatah MSc, Ahmed Abdellatif MD, et al.Outcome of Ilizarov External Fixator for Treatment of Comminuted Tibial Plateau Fractures. Ortho Res Online J. 6(5). OPROJ.000648.2020. DOI: $10.31031 /$ OPROJ.2020.06.000648

Copyright@: Ebeed yasin, This article is distributed under the terms of the Creative Commons Attribution 4.0 International License, which permits unrestricted use and redistribution provided that the original author and source are credited.
Ebeed yasin MD $^{1 *}$, Faisal Adam MD $^{2}$, Hesham Refae MD $^{1}$, Abdallah Hussein Abdel-Fatah MSc ${ }^{1}$, Ahmed Abdellatif MD', Morsy Basiony MD $^{1}$ and Mohamed Salman $\mathrm{MD}^{1}$

${ }^{1}$ Orthopaedic Department, Aswan University, Egypt

${ }^{2}$ Orthopaedic Department, Assiut University Hospital, Egypt

\section{Summary}

Background: Comminuted tibial plateau fractures (CTPF) almost associated with intraarticular extension and various degree of soft tissue injury. Ilizarov fixator provides a rigid fixation for these fractures and allows immediate mobilization of the joints and early weight bearing.

Purpose: evaluation of results of the Ilizarov ring fixator method in patients with CTPF regard to union, complication rates and final functional outcome.

Methods: A prospective cohort study was carried out for patients with CTPF in Aswan University Hospital and Assiut University Hospital utilizing ilizarov ring external fixator.

Material: Twenty consecutive patients with CTPF were classified according Schatzker's classification; 9 patients were type VI, 7 patients were type V and 4 patients were type IV, 17 open and 3 closed fractures. The mean age was 34.05 (ranged from 20-54) years, 16 male and 4 females.

Results: All fractures united at a mean time 21 (ranged from 14 to 25) weeks. The ilizarov fixators were removed after mean of 16.5 (range from 13 to 29) weeks. The average follow up was 19 (range 15-24) months. The outcome was excellent in 12, good in 6 and fair in 2 according the rating system of Hospital for Special Surgery (HSS knee score). Five cases recorded malunion. The final knee range of motion ranged from $0^{\circ}$ to $160^{\circ}$ with mean $105^{\circ}$ with cases of schatzker, type $\mathrm{V}$ and VI, while type IV fractures had $125^{\circ}$ mean knee range. One case suffered from total stiff knee in $0^{\circ}$ extension. Three cases with ligamentus laxity but without functional disability.There was a direct correlation $(\mathrm{P}<0.005)$ between the type of the fracture and number of ilizarov rings in relation to the final outcome.

Conclusion: Ilizarov fixator allows early definitive treatment with early weight-bearing in CTPF with low complication rate in either extra-articular or intra-articular fractures.

Keywords: Ilizarov; External fixator; Metaphyseal; Tibial; Fractures

Introduction

Comminuted tibial plateau fractures (CTPF) tibia present a wide spectrum of soft tissue and bony injury patterns that may be associated with permanent functional disability [1] either by the severity of the injury or operative complications [2]. Various degree of soft tissue complication and chronic infection are associated with treatment of these fractures using the plates and screws even with single anterior or double surgical approaches. Many operative techniques are published to minimize the osseous and soft tissue devascularization to decrease the complications [3]. Now days there was a shift from internal fixation to external fixation especially to the ilizarov ring fixator $[4,5]$, that allows immediate definitive fixation, early mobilization of the joints and early weight bearing [6]. The tensioned wires of ilizarov frame achieve a stable fixation in the cancellous fragment. Ilizarov external fixator is minimally invasive simple fixator that reduces the surgical time and trauma [7].

\section{Aim of the Work}

Evaluation of the results of the Ilizarov ring fixator method in patients with CTPF regard to union, complication rates and final functional outcome.

\section{Patients and Methods}

Twenty consecutive patients with CTPF from June 2016 to May 2019 were treated in orthopaedic department, Aswan University Hospital. The mean age was 34.05 (ranged from 
20-54) years, 16 male and 4 females. The inclusion criteria were severely comminuted open or closed tibial plateau fractures. The exclusion criteria were bed ridden patients and negligent patients. High Energy Trauma was the cause in all cases and motor car accidents was the major cause (75\%). According Schatzker's classification [8]; 9 patients were type VI, 7 patients were type $\mathrm{V}$ and 4 patients were type IV. As regard to associated soft tissue injury; 3 cases with closed fracture Tscherene III [9] and 17 cases with open fractures; according to Gustello classification [10], 4 cases were gustello I, 7 cases were gustello II, 4 cases were IIIA, and 2 cases were IIIB. Time of surgery starts from day one up to 3 weeks after trauma. Patients with open fracture were treated in causality with debridement and definitive fixation by ilizarov. Prophylactic antibiotics were administered intravenously in all cases. Preoperative radiographic workup included standard x rays; anteroposterior (AP) and lateral knee, tibia and ankle, as well as computed tomography (CT) scans to better evaluate the fracture fragment/pattern and articular surface.

\section{Operative technique}

Spinal anesthesia was used in all cases. The patients were positioned on a radiolucent operating table in the supine position. The limb from thigh to foot was sterilized and draped. The fluoroscopy was used during the steps of the reduction and pin insertion. The surgery was performed without a tourniquet. The ilizarov frame was assembled preoperatively. Percutaneous fasciotomy was performed in 5 patients where the compartmental syndrome was suspected. Many techniques described the surgical steps of ilizarov frame for fixation of CTPF [11-15]. The aim was reduction of the displaced tibial condyles with anatomical reduction of the articular surfaces and restoration of stable normal alignment of the tibial shaft beneath the tibial condyles. The helpful reduction tools were the ligamentotaxes (in all cases) through the axial traction with side to side adjustment and using large pointed forceps for accurate reduction of condylar and compression of fracture gaps. Large diameter $\mathrm{k}$ wires (in 6 cases), small osteotome ( in 4 cases) or mosqute (in 3 cases) were used sometimes through a percutaneous (in 8 cases) or minimal skin approach (in 5 cases) for manipulation of bone fragments and disimpaction of the dypunch bony fragment to achieve nearly anatomical reduction of the articular surfaces. The preassembled ilizarov frame, consisting of three rings appropriately matched with the leg size connected by threaded rods to each other, the proximal ring was then fixed to the inserted olive wires that already transfixed into the tibial condyle under the articular surface. The position of the middle ring was adjusted distal to any metaphyseal-diaphyseal fracture lines and the distal ring was fixed distally by transfixion reference wires parallel to the transverse orientation line of the ankle joint to reconstruct the normal mechanical axis of the tibia. Knee spanning using distal femoral ring was done in 5 cases, 3 of them with ligamentous knee injury and 2 cases were severe fracture comminution, the tibial and femoral component were connected through 2 uniplanar hinges that located at the both side of knee and adjusted at the axis of knee rotation. Knee exercises were started gently early postoperative on the second day while the weight bearing was started after 6 weeks All patients were followed up in the outpatient clinic for an average 19 (range 15-24) months, where, the final outcome is evaluated according to Rasmussen's criteria [16] and the rating system of Hospital for Special Surgery (HSS knee score) $[17,18]$.

Results

Table 1: Complications between HSS knee score evaluation groups.

\begin{tabular}{|c|c|c|c|c|c|c|}
\hline & \multirow{3}{*}{$\begin{array}{c}\text { Fair } \\
\text { N (\%) }\end{array}$} & \multicolumn{3}{|c|}{ HSS Knee Score Evaluation } & \multirow{2}{*}{\multicolumn{2}{|c|}{ Monte Carlo (Fisher's Exact) Test }} \\
\hline & & \multirow{2}{*}{$\begin{array}{c}\text { Good } \\
\text { N (\%) }\end{array}$} & \multirow{2}{*}{$\begin{array}{c}\text { Excellent } \\
\mathrm{N}(\%)\end{array}$} & \multirow[b]{2}{*}{ P-Value } & & \\
\hline & & & & & Sig. & \\
\hline \multirow{4}{*}{ 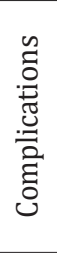 } & No & & $3(60 \%)$ & $\begin{array}{c}11 \\
(84.62 \%)\end{array}$ & \multirow{4}{*}{0.013} & \multirow{4}{*}{ S } \\
\hline & Pin tract infection & & $2(40 \%)$ & $2(15.38 \%)$ & & \\
\hline & flexion deformity & $2(50 \%)$ & & & & \\
\hline & 10 degrees Varus deformity & $1(25 \%)$ & & & & \\
\hline & Stiff knee & $1(25 \%)$ & & & & \\
\hline
\end{tabular}

All patient in our study show radiological complete union at a mean time 21 (ranged from 14 to 25) weeks. Any metaphyseal voids were healed without need to bone graft or bone substitutes. All cases treated with ilizarov frame without the need to minimal internal fixation. The mean hospital stay was 3 days that ranged from 2 to 5 days. The ilizarov fixators were removed after mean of 16.5 (range from 13 to 29) weeks. One patient suffered from DVT at two weeks postoperatively and was successfully treated by rest and anticoagulant drugs. The final clinical and radiological outcome of the treated cases was scored according to Rasmussen's criteria; clinically and radiologically [16], as excellent in 12, good in 5 , fair in 2 and poor in 1 . The outcome according the HSS knee score [17] was excellent in 12, good in 6 and fair in 2, where $100 \%$ of type $\mathrm{V}$ recorded excellent results and $71.4 \%$ in typeIV while type VI $33.30 \%$ were excellent. five cases of malunion occurred; one case with $10^{\circ}$ varus deformity and two cases had broadening of tibial plateau 6-10 $\mathrm{mm}$ and two cases with intraarticular step about $4 \mathrm{~mm}$ in lateral tibial plateau. These malunited cases presented with 
painless full range of motion without function disability except the varus case that needed later corrective osteotomy (Table 1). The final knee range of motion ranged from $0^{\circ}$ to $160^{\circ}$ with mean $105^{\circ}$ with cases of schatzker, type V and VI, while type IV fractures had $125^{\circ}$ mean knee range (between $0^{\circ}$ and 170 ). Two cases (schatzker VI) suffered from knee flexion deformity, one case with $5^{\circ}$ and the other with $12^{\circ}$, during the first four months after removal of the frame and finally improved totally with physiotherapy within 2 months. One case suffered from total stiff knee in $0^{\circ}$ extension and improve somewhat with physiotherapy then open surgical release was underwent followed with physiotherapy for 6 months and finally the knee range improved to be from $0^{\circ}$ to $80^{\circ}$. Ligamentus laxity in form of positive varus stress (two case schatezker type $\mathrm{V}$ and VI) and valgus stress (one case type VI) but without functional disability (Table 1).

Hinged knee spanning for 8 weeks using one distal femoral ring was needed in $50 \%$ of schatzker type VI. Spanning decreased the pain and improved range of motion. $40 \%$ suffered from mild pin tract infection that controlled with antibiotics and betadine dressing, and finally resolved after removal of the frame (Table 1). Osteomyelitis, compartmental syndrome or nerve injuries didn't document between cases in our study. Percutaneous fasciotomy was performed in 5 cases as a prophylactic to avoid the compartmental syndrome as it is was suspected. There was a direct correlation ( $\mathrm{p}$ value $<0.005$ ) between the type of the fracture in relation to the final outcome (Table 2). The degree of open fractures didn't affect the final outcome (p value 0.72) (Table 3).

Table 2: Schatzker's classification in tibial plateau group between HSS knee score evaluation groups.

\begin{tabular}{|c|c|c|c|c|c|c|}
\hline & & \multicolumn{3}{|c|}{ HSS knee score evaluation } & \multirow{2}{*}{\multicolumn{2}{|c|}{ Monte Carlo (Fisher's Exact) Test }} \\
\hline & Fair & Good & Excellent & & & \\
\hline & \multicolumn{3}{|c|}{ Number of patients } & P-Value & Sig. & \\
\hline \multirow{3}{*}{ Schatzker's classification } & Type IV & 0 & 0 & 4 & \multirow{3}{*}{0.028} & \multirow[b]{3}{*}{$\mathrm{S}$} \\
\hline & Type V & 0 & 2 & 5 & & \\
\hline & Type VI & 2 & 4 & 3 & & \\
\hline
\end{tabular}

Table 3: Open or closed fracture between HSS knee score evaluation groups.

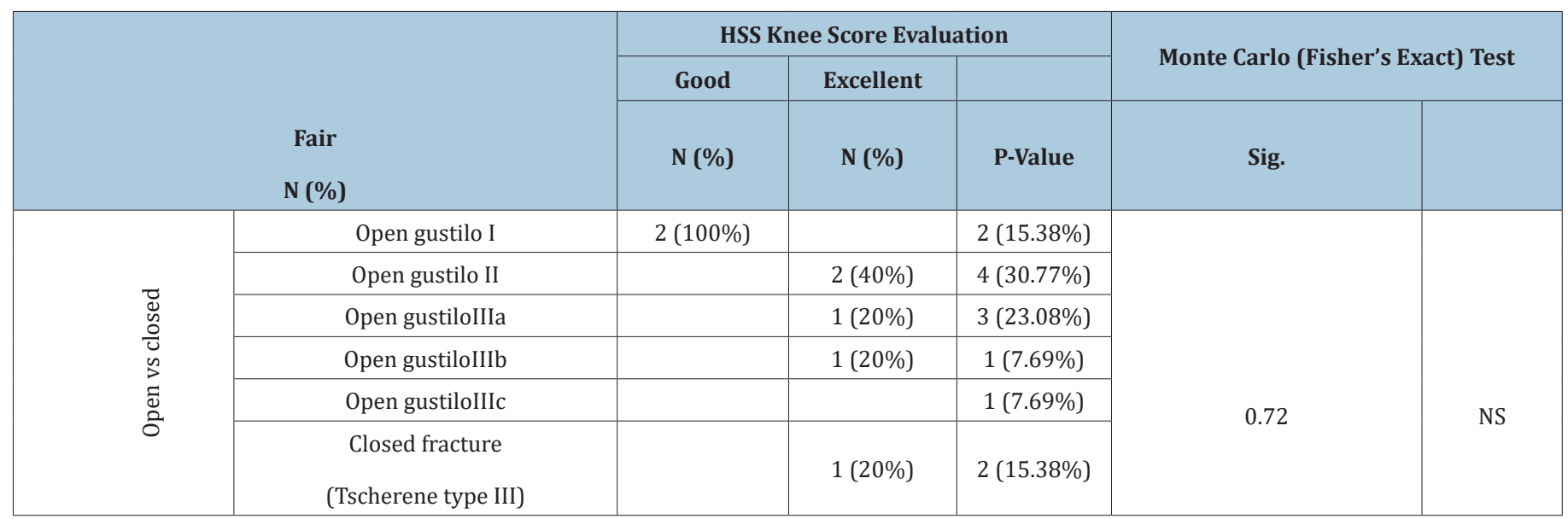

\section{Discussion}

Treatment of intra-articular CTPF is a challenging mission as it includes a wide spectrum of soft tissue and bony injuries that can produce permanent functional impairments [1]. Ilizarov fixator facilitates safe management of these complex fractures that associated the soft-tissue injury [10], especially when the internal fixation will be certainly harmful. As the fracture blisters or extensive subcutaneous hemorrhage and bruising does not prevent percutaneous placement of the wires. The transfixing ilizarov wires preserve the periosteal and endosteal blood supply of fractured bones and its soft tissue sleeve [19,20]. In our study, 5 patients $(25 \%)$ required a minimal skin incision $(3-5 \mathrm{~cm})$ to just elevation of depression of the tibial plateau, where, 8 patients (40\%) needed only percutaneous manipulation through just skin stab wound $(1-2 \mathrm{~cm})$ using large diameter $\mathrm{k}$ wire, mosqute or small osteotome for disimpaction and reduction of the depressed small bone fragments without knee arthrotomy. Barbary et al use minimal incision 5-6cm in 30\% of cases [14]. Many authors use the open reduction and arthrotomy for this job; 79\% open reduction with Watson [15], 50\% open reduction with Dendrinos et al. [12] and $60 \%$ open reduction with Weiner et al. [21]. In our study the fixation is achieved with the ilizarov only without any need for additional internal fixation with lag screws as done with Dendrinos et al. [12]. On the other hand, Weiner et al. [20] used lag screw fixation with all intraarticular fractures and Barbary et al used lag 
screws in $60 \%$ of their cases [19]. The use of bone graft is popular to fill the subchondral metaphyseal defect after elevation of the depressed articular surface was 26\% with Morandi and Pearse [20], $57 \%$ with Watson and Coufa grafting [15] and 16.6\% with Barbary et al. [19], while in our study we didn't use any bone graft and any metaphyseal defects in all cases rapidly disappeared while the fractured uniting. In our study, the mean time for ilizarov fixation to achieve complete fractures union was 5.3 month (ranged from 3.5 to 6.3 months) which is almost similar to the reported union rate in other literatures $[12,15,19]$, where, the final radiological and clinical outcome according to Rasmussen criteria showed excellent in 12 , good in 5 , fair in 2 and poor in 1 , which is comparable the published results in the similar studies [12,15,21], while other study was superior [19]. The final mean knee range of motion in our study was $105^{\circ}$ with type V and VI fractures and $125^{\circ}$ with type IV fractures in our study after exclusion of the stiff knee case. Other studies the mean range ranged from 90 to 120 [19,20,22,23]. Instability of the knee after these fractures, whether improper healed ligamentous injuries or bone deformity, is a major cause of a poor result [20]. The repair of associated ligament injuries at the time of the fixation of the fracture is a major debatable issue [24]. The extended tibiofemoral circular fixation provides adequate bracing and allow healing in the optimal direction and length for the injured knee ligaments. In our study we used femoral ring in 4 cases $(20 \%)$ which all of them were tibial plateau fractures type VI and successfully healed without any gross instability. The external fixators have a risk of skin-penetrating infections (pin site and pin tract infections). The ilizarov ring fixators had the lowest incidence of infection compared with unilateral and hybrid fixator [25]. The incidences of pin tract infections reported in our study were 4 cases that treated successfully without any residual osteomyelitis, comparable to the published literatures [19]. While the deep infection and chronic osteomyelitis were documented with a variable percentage with the use of the plates and screws $[6,26]$. The relationship between the anatomical reduction and the final outcome, also how much the amount of residual deformity that can be accepted is still controversial [8,10,12,15,21,26-28], where it is difficult to use the anatomical radiological finding as a prognostic factor for patient satisfaction because there are no correlation between the postoperative radiological findings and the final clinical outcome [19], as documented in our study. Also, the most important finding in this study was the satisfactory outcome of the Ilizarov method, independently of fracture pattern. In our study five cases of malunion occurred although they presented with painless full range of motion without function disability except one case with $10^{\circ}$ varus which needed later corrective osteotomy (Table 1). Also 3 cases presented with ligamentus laxity in form of positive varus and valgus stress but without functional disability. Open injuries represent $85 \%$ in our study and were statistically nonsignificant for the final outcome ( $p$-value; 0.72 ), while with Barbary et al. [29] the open injuries were associated with $45 \%$ of the unsatisfactory results. Ilizarov fixator allows both early weightbearing and early range of motion. Early weight-bearing stimulates callus formation and preserve the muscular strength [29]. The early postoperative loading of the tibial plateau fractures should be prevented to avoid loss of fracture reduction that may be leading to knee valgus deformity or the articular surface depression [30]. So, in our study we delayed the weight bearing on the injured limb for 6 weeks but allowed for early postoperative range of motion.

\section{Conclusion}

The Ilizarov technique is a safe and reliable method that allows early definitive treatment and unrestricted weight-bearing for CTPF regardless to soft-tissue damage and achieve a satisfactory outcome with low complication rate in both the extra-articular and the intra-articular fractures.

\section{References}

1. Salter RB, Ogilvie Harris DJ (1979) Healing of intra-articular fractures with continuous passive motion. AAOS Instructional Course Lectures 28: 102-117.

2. Sirkin M, Sanders R (2001) The treatment of pilon fractures. Orthopaedics Clinics 32(1): 91-102.

3. Dillin L, Slabaugh P (1986) Delayed wound healing, infection, and nonunion following open reduction and internal fixation of tibial plafond fractures. J Trauma 26(12): 1116-1119.

4. French B, Tornetta P (2000) Hybrid external fixation of tibialpilon fractures. Foot Ankle Clin 5(4): 853-871.

5. Schatzker J (1988) Fractures of the Tibial Plateau. In: Schatzker J, Tile M (Eds.), The Rationale of Operative Orthopaedic Care, Springer-Verlag, New York, USA, Pp: 279-295.

6. Mallik AR, Covall DJ, Whitelaw GP (1992) Internal versus external fixation of bicondylar tibial plateau fractures. Orthop Rev 21(12): 1433-1436.

7. Yang L, Saleh M, Nayagam S (2000) The effect of different wire and screw combinations on the stiffness of hybrid external fixator. Journal of Engineering in Medicine 214(6): 669-676.

8. Schatzker J, McBroom R Bruce D (1979) The tibial plateau fracture. The toronto experience 1968-1975. Clin Orthop Relat Res 138: 94-104.

9. Tscherne H, Gotzen L (Eds.), (1984) Fractures with soft tissue injuries. Springer, Berlin Heidelberg, USA.

10. Gustilo RB, Anderson JT (1976) Prevention of infection in the treatment of one thousand and twenty-five open fractures of long bones. J Bone Joint Surg Am 58(4): 453-458.

11. Buckle R, Blake R, Watson JT, et al. (1993) Treatment of complex tibial plateau fractures with the Ilizarov external fixator. J Orthop Trauma 7: 167.

12. Dendrinos GK, Kontos S, Katsenis D, Dalas A (1996) Treatment of high-energy tibial plateau fractures by the Ilizarov circular fixator. J Bone Joint Surg Br 78(5): 710-717.

13. Gustilo RB, Mendoza RM, Williams DN (1984) Problems in the management of type III (severe) open fractures: A new classification of type III open fractures. J Trauma 24(8): 742-746.

14. Kumar A, Whittle AP (2000) Treatment of complex (Schatzker type VI) fractures of the tibial plateau with circular wire external fixation: Retrospective case review. J Orthop Trauma 14(5): 339-344.

15. Watson JT, Coufal C (1998) Treatment of complex lateral plateau fractures using Ilizarov techniques. Clin Orthop Relat Res 353: 97-106.

16. Rasmussen PS (1973) Tibial condylar fractures: Impairment of knee joint stability as an indication for surgical treatment. J Bone Joint Surg Am 55(7): 1331-1350. 
17. Leunig M, Hertel R, Siebenrock K, Ballmer FT, Mast JW, et al. (2000) The evolution of indirect reduction techniques for the treatment of fractures. Clin Orthop Relat Res 375: 7-14.

18. (2007) Comparison of treatment results in knee osteoarthritis-applicability of point systems. Kessler S, Käfer W (Eds.), Comparative assessment of outcome in osteoarthritis of the knee: The utility of knee scores. Acta Chirurgiae Orthopaedicae Et Traumatologiae Chechosl 74: 332-335.

19. El Barbary H, Abdel Ghani H, Misbah H, Salem K (2005) Complex tibial plateau fractures treated with Ilizarov external fixator with or without minimal internal fixation. Int Orthop 29(3): 182-185.

20. Morandi M, Pearse MF (1996) Management of complex tibial plateau fractures with the Ilizarov external fixator. Tech Orthop 11: 125-131.

21. Weiner LS, Kelley M, Yang E, Steuer J, Watnick N, et al. (1995) The use of combination internal fixation and hybrid external fixation in severe proximal tibia fractures. J Orthop Trauma 9(3): 244-250.

22. Zecher SB, Danziger MB, Segal D, Foster T, Whitelaw GP, et al. (1996) Treatment of high-energy proximal tibial fractures using the MonticelliSpinelli external fixator: A preliminary report. Am J Orthop 25(1): 49-54
23. Lansinger O, Bergman B, Korner L (1986) Tibial condylar fractures. A twenty-year follow-up. J Bone Joint Surg Am 68(1): 13-19.

24. Delamarter RB, Hohl M, Hopp E (1990) Ligament injuries associated with tibial plateau fractures. Clin Orthop Relat Res 12(250): 226-233.

25. Parameswaran AD, Roberts CS, Seligson D, Michael Voor (2003) Pin tract infection with contemporary external fixation: How much of a problem? J Orthop Trauma 17(7): 503-507.

26. Young MJ, Barrack RL (1994) Complications of internal fixation of tibial plateau fractures. Orthop Rev 23(2): 149-154.

27. Marsh JL, Buckwalter J, Gelberman R, Dirschl D, Olson S, et al. (2002) Articular fractures: Does an anatomic reduction really change the result? J Bone Joint Surg Am 84(7): 1259-1271.

28. Hefny HM (2000) Treatment of complex tibial plafond injuries using Ilizarov methodology. Pan Arab J Orthop Trauma 4: 37-42.

29. Scotland T, Wardlaw D (1981) The use of cast-bracing as treatment for fractures of the tibial plateau. J Bone Joint Surg Br 63(4): 575-578.

30. Apley AG (1956) Fractures of the lateral tibial condyle treated by skeletal traction and early mobilisation: A review of sixty with special reference to the long-term results. J Bone Joint Surg Br 38(3): 699-708. 